\title{
Memorias del primer amor
}

\author{
Alicia Cayssials* \\ Marcelo Pérez** \\ Ana D'Anna**
}

\section{Resumen}

En el presente trabajo, de tipo descriptivo, se analizan las respuestas de 800 sujetos adultos argentinos, entre 30 y 60 años de edad, a una técnica elaborada para evaluar las memorias del primer amor y su significación. Los resultados muestran que los sujetos refieren haberse enamorado por primera vez alrededor de los 15 años de edad. Las mujeres refieren con mayor frecuencia que los varones, haberse enamorado por primera vez de una persona de mayor edad que ellas. El 30\% de los sujetos refiere que este primer amor fue "platónico", mientras que el 70\% declara haber sido correspondido. Menos del 10\% de los participantes afirma recordar con frecuencia a su primer amor. En el diferencial semántico administrado, los adjetivos elegidos para significar al primer enamoramiento son: bueno, lindo, sincero, limpio, valioso, agradable, saludable y positivo. El primer amor es idealizado en el momento en que la experiencia es vivida; los datos obtenidos permiten afirmar a su vez que su recuerdo conserva también esta característica.

Palabras clave: Memoria. Primer amor. Adultos. Diferencial Semántico.

\section{Abstract}

\section{FIRST LOVE 'S MEMORIES}

The current paper analyses the answers of 800 Argentine adults, aging from 30 to 60 years old, to a technique that evaluates memories of the first love and its meaning. Results show that participants refer to have fallen in love for the first time when being around 15 years old. Women express much more frequently than men to have fallen in love for the first time with an older person. $30 \%$ of the subjects qualify this first as platonic and not coresponded love meanwhile $70 \%$ express to have been returned. Less than $10 \%$ of persons participating in this rese-

* Profesora adjunta regular. Facultad de Psicología. Universidad de Buenos Aires. E-mail: alicayss@psi.uba.ar.

** Docentes de la Facultad de Psicología UBA. Profesores en la Universidad de Palermo. Carrera de Psicología. 
rach affirm they frequently remember that experience. Along the given semantic differential, the chosen adjetives to describe the first being (falling) in love experience are: good, nice, sincere, clean, valuable, pleasant, healthful and positivve. Data gathered let us affirm that the first love is idealized not only during experiencig it, but also when it is remembered.

Key words: Memory. First love. Adults. Semantic differential. 


\section{Introducción}

La importancia del primer amor, si bien es rescatada desde distintos saberes, no ha sido hasta el momento estudiada por la ciencia psicológica de modo sistemático. Entre los escasos autores que se han ocupado del tema encontramos al sociólogo italiano Alberoni que publicó en 1997 su obra El primer amor. Define al enamoramiento como una atracción repentina, un fuerte deseo de estar con la otra persona, un "flechazo", una atracción estética, una preferencia inmediata, en donde todos los viejos vínculos pierden importancia y se impone luminoso el nuevo objeto de amor con el que se desea fundirse física y psicológicamente.

La persona amada no es sólo alguien que a uno le gusta mucho, como sucede en los arrebatos, sino "la mejor del universo" pues tiene las propiedades de lo absoluto. El enamoramiento, aclara Alberoni, surge de repente como la erupción de un volcán.

Una de las facetas que este autor investiga con más detalle es cómo las personas de distintos grupos etáreos responden a la pregunta "¿a qué edad tuvo el primer amor?".

Ante este interrogante encuentra que los participantes refieren su primer amor por un lado a edades muy tempranas y por otro muestran una tendencia a ubicarlo más cercano en el tiempo. Interpreta entonces que el primer amor, en éste ultimo caso, se ha reelaborado y sepultado en el olvido.

El tema que nos ocupa incluye también los estudios actuales sobre la memoria. El cerebro humano contiene cerca de diez mil millones de neuronas conectadas entre sí de formas muy complejas. Como menciona LeDoux (1999), la proeza más sorprendente y complicada que cumple es la creación de las emociones. Las emociones son funciones biológicas del sistema nervioso que están representadas en el cerebro. Este enfoque es radicalmente distinto del que estudia las emociones como estados psicológicos, independientes de los mecanismos cerebrales. La investigación psicológica, extremadamente valiosa, puede nutrirse de este enfoque en el cual las emociones son estudiadas como funciones cerebrales.

Freud fue el primero en explicar que es el inconsciente donde se asientan nuestras emociones y que a menudo están disociadas de los procesos normales del pensamiento. Actualmente se sabe que existen múltiples mecanismos de memoria en el cerebro y que cada uno de ellos realiza funciones específicas. Los diversos tipos de memoria, al igual que los diferentes tipos de emociones y sensaciones proceden de distintos mecanismos cerebrales (LeDoux. 1999). 
Hoy día es generalizada también la noción de la existencia de un almacenamiento de la memoria a corto plazo, que dura unos segundos, y uno a largo plazo, que puede durar desde unos minutos hasta toda una vida.

Los neuropsicólogos se refieren a los recuerdos concientes como memoria declarativa o explícita, la cual depende del mecanismo de memoria del lóbulo temporal (Cohen y Squire, 1980). Estos recuerdos son creados y pueden recordarse y describirse verbalmente.

A través de los años se han ido proponiendo distintas clasificaciones de la memoria (Tulving, 1983) pero la distinción entre la memoria declarativa, explícita y conciente, por un lado, y la memoria de procedimientos, implícita e inconsciente, por otro, ha tenido una gran resonancia en el pensamiento actual. En la siguiente tabla se presenta la clasificación relativamente consensuada del funcionamiento de la memoria.

Tabla 1. Clasificación de la memoria.

\begin{tabular}{|c|c|c|}
\hline $\begin{array}{c}\text { Sistema } \\
\text { (Términos similares) }\end{array}$ & Subsistemas & $\begin{array}{l}\text { Modalidad de } \\
\text { recuperación }\end{array}$ \\
\hline $\begin{array}{l}\text { De procedimientos o } \\
\text { procedural (No declarativa) } \\
\text { De representación } \\
\text { perceptual (No declarativa/ } \\
\text { priming) }\end{array}$ & $\begin{array}{l}\text { Habilidades motoras y cognitivas. } \\
\text { Aprendizaje asociativo y } \\
\text { condicionamiento simple. } \\
\text { Forma visual y/o auditiva de la palabra. } \\
\text { Descripción estructural. }\end{array}$ & $\begin{array}{l}\text { Implícita } \\
\text { Implícita }\end{array}$ \\
\hline $\begin{array}{l}\text { Semántica (Genérica; Factual; } \\
\text { Conocimiento) }\end{array}$ & Espacial / Relacional. & Explícita \\
\hline $\begin{array}{l}\text { Primaria (Working memory/ } \\
\text { a corto plazo) }\end{array}$ & Visual / Auditiva. & Explícita \\
\hline $\begin{array}{l}\text { Episódica (Personal; } \\
\text { Autobiográfica, de eventos) }\end{array}$ & & Explícita \\
\hline
\end{tabular}

Los trabajos de Tulving (1972) han permitido diferenciar la memoria episódica de la semántica, es decir, aquella que almacena hechos y sucesos vitales de aquella que almacena la lengua hablada. El tipo de memoria episódica es especialmente vulnerable al paso del tiempo. Como demostró Bartlett (1932) hace ya mucho tiempo, los recuerdos explícitos comportan simplificaciones, adiciones, elaboraciones y racionalizaciones de las experiencias así como omisiones de elementos.

Recordar es ser conciente de alguna vivencia pasada. Cuando utilizamos la palabra memoria nos referimos a la evocación conciente. La presente investigación tiene como objetivo evaluar la memoria sobre el primer amor y para lograrlo proponemos a los sujetos la creación de recuerdos autobiográficos sobre esta experiencia singular. 


\section{Método}

Tipo de estudio: descriptivo

Muestra: Participaron (en forma voluntaria) 800 personas adultas con edades entre 30 y 60 años inclusive; la edad promedio es de 43 años con un desvío típico de 9 años. En cuanto al género, 400 pertenecen al sexo femenino y 400 al masculino, siendo el lugar de residencia del $49 \%$ la Ciudad Autónoma de Buenos Aires y del 51\% el Conurbano Bonaerense y la Provincia de Buenos Aires.

Las edades se han clasificado en tres grupos, como indicamos en la tabla 2. Se señalan a continuación las distribuciones de las frecuencias obtenidas y los respectivos porcentajes.

Tabla 2. Distribución de la muestra según la edad de los participantes.

\begin{tabular}{ccc}
\hline Grupo & Frecuencia & Porcentaje \\
\hline 30 a 39 años & 321 & $40.1 \%$ \\
40 a 49 años & 254 & $31.8 \%$ \\
50 a 60 años & 225 & $28.1 \%$ \\
\hline
\end{tabular}

En las siguientes tablas se presentan las distribuciones de frecuencias de los integrantes de la muestra según nivel de instrucción, ocupación y estado civil.

Tabla 3. Distribución de lozs participantes según el nivel de instrucción.

\begin{tabular}{ccc}
\hline Nivel de instrucción & $\mathbf{n}$ & Porcentaje \\
\hline Primario incompleto & 5 & $0.6 \%$ \\
Primario completo/ Secundario incompleto & 100 & $12.5 \%$ \\
Secundario completo/ Terciario incompleto & 401 & $50.1 \%$ \\
Terciario completo & 292 & $36.5 \%$ \\
Maestría / Doctorado & 2 & $0.3 \%$ \\
\hline
\end{tabular}

Tabla 4. Distribude los sujetos según su ocupación.

\begin{tabular}{ccc}
\hline Ocupación & $\mathbf{n}$ & Porcentaje \\
\hline Profesional. Empresario. & 153 & $19.1 \%$ \\
Comerciante. Bancario. Docente. & 395 & $49.4 \%$ \\
Obrero calificado. Chofer. & 106 & $13.3 \%$ \\
Jubilado. Ama de casa. Estudiante. Desocupado. & 137 & $17.1 \%$ \\
Otros. & 9 & $1.2 \%$ \\
\hline
\end{tabular}


Fueron agregadas además dos variables estrechamente relacionadas con la temática en estudio. La primera, referida a si actualmente tiene una pareja estable. El 79\% de los participantes contestó en forma afirmativa; el 20\% lo hizo en forma negativa; mientras que el $1 \%$ de lo sujetos dejaron la pregunta sin responder.

La segunda se refiere a si se casó o no con su primer amor. Las respuestas afirmativas alcanzan el 13\%; el $66 \%$ las negativas y el $21 \%$ de los participantes no contesta.

\section{Instrumento de recolección de datos}

Para investigar el tema de las memorias del primer amor en nuestro medio se construyó un cuestionario en el cual, luego de la pregunta básica (1) ¿¿a qué edad recuerda haberse enamorado por primera vez?", se solicita información sobre (2) la proximidad de la edad de la persona amada con la del sujeto que responde el cuestionario (véase en apéndice el Cuestionario Memorias sobre el Primer Amor).

Las preguntas (3) y (4) apuntan a deslindar si el primer amor posee o no las características del llamado amor platónico (Ackerman, 2000), en cuanto a haber sido correspondido o no, mientras que la pregunta (5) releva información sobre el tema literario y folklórico referido a la imposibilidad de olvidar al primer amor, preguntando la frecuencia con que lo recuerda.

Por ultimo, en el punto (6) se presenta la consigna del diferencial semántico construido para investigar la connotación del primer enamoramiento.

La escala de clasificación elaborada por Osgood y sus colaboradores en 1957, con el fin de medir el significado connotativo, también llamado significado afectivo o subjetivo, que determinados conceptos tienen para los sujetos, se mostró adecuada para los objetivos del presente estudio.

Durante mucho tiempo los filósofos y lingüistas han estudiado el significado de las palabras, de las frases; sin embargo los psicólogos, a pesar de su interés por desentrañar la naturaleza del lenguaje y los procesos de comunicación, tardaron en elaborar teorías del significado y métodos para investigar empíricamente el fenómeno.

Chomsky y los seguidores de su obra desarrollaron, dentro del campo de la lingüística, las teorías estructuralistas del significado, dando origen a un campo de investigación muy amplio que ha permitido a los psicólogos abordar el problema del lenguaje y la naturaleza del mismo sobre una base firme. Se propusieron luego varios modelos de aproximación al problema del significado. Osgood (1957) realizó una revisión sistemática de todas las teorías del significado y luego elaboró un marco teórico que le permitió desarrollar un instrumento: El Diferencial Semántico. Partió del supuesto de que la actitud que una persona 
muestra hacia un objeto o concepto dependerá del significado evaluativo que el mismo tiene para la persona.

El campo de aplicación del diferencial semántico (DS) ha sido y es en la actualidad muy amplio ya que, debido a su naturaleza y adaptabilidad, se ha convertido en un instrumento de medida muy utilizado y su uso es muy habitual en investigaciones en el ámbito clínico, en la medida de las actitudes, en estudios transculturales y en investigaciones sociales.

El DS no es una prueba formada por ítem concretos; en realidad se trata de una forma distinta de abordar el problema de la medida de las actitudes. La tarea de los sujetos es evaluar un determinado concepto -en este caso el primer enamoramiento- a través de una serie de escalas bipolares (Bueno/ Malo, Feo/ Lindo, etc.). Por lo tanto, hay dos elementos fundamentales en el diferencial semántico: los conceptos y las escalas bipolares. Ambos dependerán de la investigación que se desee realizar. El concepto en cuestión aparece siempre encabezando la evaluación y debajo el conjunto de escalas bipolares.

El concepto debe de tener un significado claro y único para el sujeto de manera que cuando se lo presenta sepa lo que está juzgando. En la presente investigación en un principio se administró el DS con el concepto primer amor, pero esto promovía diversos interrogantes a los sujetos que respondían el cuestionario y a distintas formas de interpretar la experiencia que debían valorar. El estudio piloto realizado identificó al concepto primer enamoramiento como más simple y claro para los participantes en la investigación.

En cuanto a las escalas semánticas bipolares, cada una de ellas representa una reacción de tipo afectivo hacia el concepto (Bueno/ Malo, Sano/ Enfermo) y lo que se pretende es utilizarlas de manera que se pueda obtener una medida del significado afectivo del concepto para cada sujeto.

La selección de las escalas bipolares se realizó a través de un muestreo luego del cual se seleccionaron aquellos adjetivos que resultaron más relevantes y representativos para la muestra de sujetos. Las escalas están ancladas en sus extremos por dos adjetivos antónimos que describen un aspecto del continuo semántico a lo largo del cual se sitúa el concepto evaluado. En general, el continuo se encuentra dividido en siete categorías, aunque se puede utilizar otro número. La tarea del sujeto consiste en evaluar el concepto y clasificarlo en función de la relación que encuentre entre éste y uno de los polos de cada escala. Cuando un sujeto clasifica un concepto en la categoría media (4), se considera que para él no hay asociación ni relación semántica entre el concepto y la escala bipolar utilizada.

\section{Datos obtenidos}

El siguiente gráfico muestra la dispersión de la edad en la que los sujetos se ena- 
moraron por primera vez. El modo, el valor de mayor frecuencia, se encuentra en los 15 años. El intervalo de edad señalado por casi el 50\% de los sujetos es el que se extiende desde los 14 a los 17 años y esta distribución se presenta muy similar entre individuos de distinto sexo y diferentes edades.

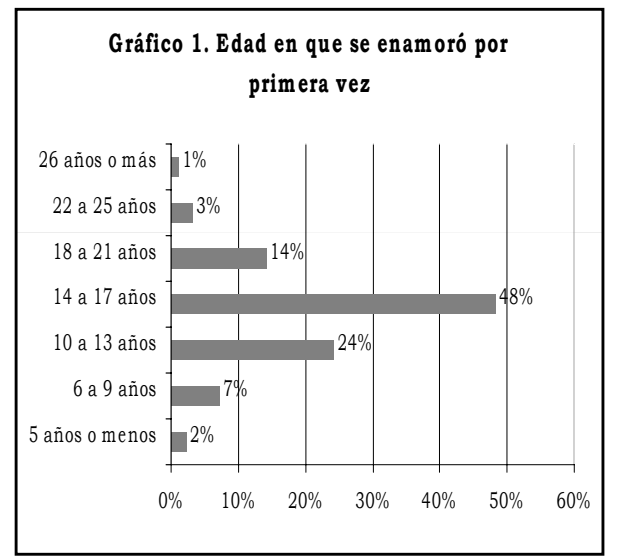

Recordemos que las personas que participaron tienen una edad entre los $30 \mathrm{y}$ los 60 años. El sujeto que ubica más tempranamente la edad en que recuerda el haberse enamorado por primera vez lo hace a los tres años, aunque la gran mayoría la ubica más tardíamente. La distribución de los datos obtenidos en la muestra puede ser interpretada por los efectos de la amnesia infantil. Este tipo de amnesia, caracterizada como la incapacidad para recordar experiencias de la niñez temprana, aproximadamente antes de los tres años de edad, fue teorizada por primera vez por Freud. Años más tarde se planteó que la clave de este fenómeno es el período de desarrollo relativamente prolongando del hipocampo (Jacobs y Nadel, 1985). Estos autores sostienen que no almacenamos recuerdos explícitos de la niñez temprana porque el mecanismo que permite elaborarlos todavía no está maduro.

Ninguno de los sujetos ubica a su primer enamoramiento después de los 40 años. El umbral máximo fue señalado por un sujeto, que lo ubicó a los 37 años.

Los valores mínimos y máximos mencionados tienen el valor de informaciones extremas (outlines) ya que la gran mayoría de los sujetos señalan la pubertad y la adolescencia como el ciclo vital durante el cual se enamoraron por primera vez y esto es independiente de su sexo, edad, ocupación, lugar de residencia o estado civil actual. 
Por otro lado, a partir de estos valores analizamos la posible existencia de una relación entre la edad en que los sujetos se enamoran por primera vez y su edad actual. Los datos no presentaron evidencia empírica acerca de una relación significativa (coeficiente de correlación de Pearson $=.32$ ). Sin embargo, se podría afirmar que la primer relación amorosa, una vez establecida en la memoria, queda fijada o se acerca en el tiempo.

Se hallaron diferencias estadísticamente significativas (p-valor $<0.01$ ) según género en las respuestas sobre la edad de la persona de quién se enamoraron. Las mujeres refieren, con mayor frecuencia (54\%) que los varones (31\%), haberse enamorado por primera vez de una persona mayor que ellas.

En cuanto a si este primer amor fue correspondido por la persona amada, alrededor del $70 \%$ de los sujetos respondió positivamente, sin encontrar diferencias según la edad. En el 30\% restante el primer amor fue "platónico", no correspondido y recuerdan haberlo vivido alrededor de los 13 años. Los mismos sujetos señalan que el primer amor, esta vez correspondido, lo vivieron, en promedio, a los 19 años.

Los integrantes de la muestra de distintas edades responden de manera similar con respecto a la frecuencia con que recuerdan al primer amor. El $9 \%$ lo recuerda frecuentemente; el $27 \%$, a veces; el $43 \%$ casi nunca y nunca el $19 \%$.

La mayoría de las personas recuerda a su primer amor pocas veces en su vida. En esta variable, como en el resto, no se encontraron diferencias estadísticamente significativas según el nivel educativo de los participantes en el estudio.

Con el fin de analizar los resultados arrojados por el DS se establecieron distintos criterios a través de los cuales se clasificaron las respuestas de los sujetos a los distintos adjetivos propuestos en cuatro grupos.

En la siguiente tabla se puede observar que de los diecisiete adjetivos, ocho muestran una distribución de frecuencias similares, caracterizadas por el hecho de que el $70 \%$ o más de las elecciones se concentran alrededor de uno de los polos. Además, la barra correspondiente a la respuesta extrema por lo menos duplica en magnitud a la siguiente. Queda así delimitado un primer grupo de adjetivos que connota la significación del primer enamoramiento: bueno/ lindo/ sincero/ limpio/ valioso/ agradable/ saludable/ positivo. Todos estos adjetivos integran el factor de evaluación, teorizado por Osgood (1957). Se trata de un factor de primer orden que presenta el nivel de saturación más importante en las investigaciones llevadas a cabo con el DS. 
Psicodebate. Psicología, Cultura y Sociedad

Tabla 6. Distribución de las respuestas en el primer grupo de adjetivos.

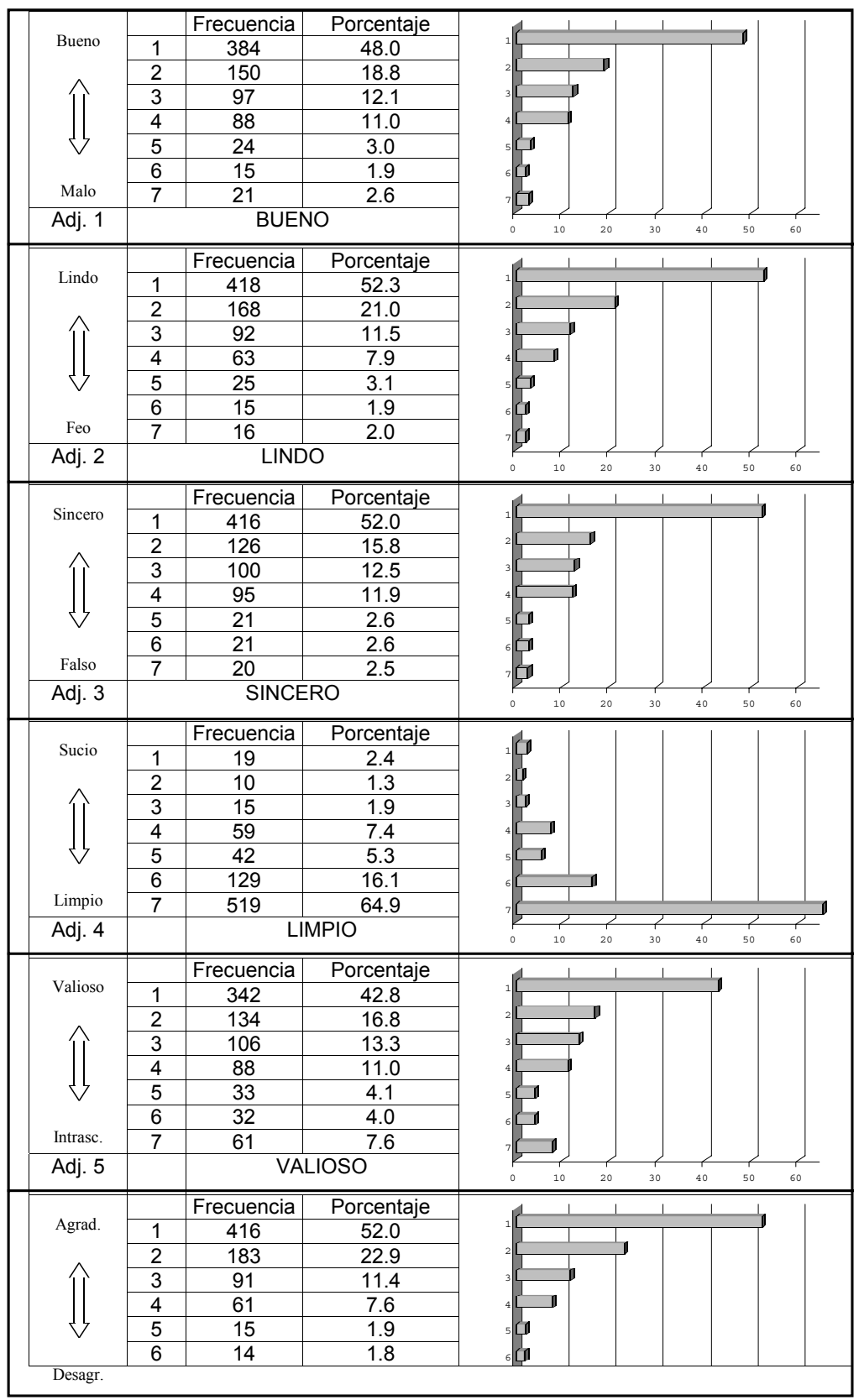


Las respuestas ante el tercer grupo de adjetivos se distribuyen de modo similar entre los distintos valores de la escala y presentan también una frecuencia alta en el valor neutro (4). Esta última característica, junto con la alta dispersión de los datos, cuestionan a estas bipolaridades como descriptores válidos para medir la significación del concepto. Los adjetivos activo/ pasivo/ fácil/ difícil y loco/ cuerdo, según la clasificación de Osgood, integran los factores 3, actividad orientada y 4, estabilidad. Los sujetos participantes no los encontraron pertinentes para valorar el primer enamoramiento.

Tabla 8. Distribución de las respuestas en el tercer grupo de adjetivos.

\begin{tabular}{|c|c|c|c|c|c|c|c|c|c|}
\hline \multirow[b]{2}{*}{ Activo. } & & Frecuencia & Porcentaje & \multirow{2}{*}{\multicolumn{3}{|c|}{ 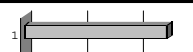 }} & & & \\
\hline & 1 & 203 & 25.4 & & & & & & \\
\hline \multirow[b]{2}{*}{$\hat{\jmath}$} & 2 & 94 & 11.8 & & & & & & \\
\hline & 3 & 115 & 14.4 & \multirow{2}{*}{\multicolumn{2}{|c|}{ 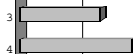 }} & & & & \\
\hline & 4 & 160 & 20.0 & & & & & & \\
\hline \multirow[b]{3}{*}{ Pasivo. } & 5 & 49 & 6.1 & \multirow{3}{*}{ (1) } & & & & & \\
\hline & 6 & 53 & 6.6 & & & & & & \\
\hline & 7 & 117 & 14.6 & & & & & & \\
\hline Adj. 7 & \multicolumn{3}{|c|}{ ACTIVO/PASIVO } & 10 & 20 & 30 & 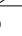 & 50 & 60 \\
\hline \multirow[b]{2}{*}{ Fácil } & & Frecuencia & Porcentaje & \multirow{4}{*}{ (1) } & & & & & \\
\hline & 1 & 94 & 11.8 & & & & & & \\
\hline & 2 & 74 & 9.3 & & & & & & \\
\hline \multirow[b]{5}{*}{ Difícil. } & 3 & 98 & 12.3 & & & & & & \\
\hline & 4 & 167 & 20.9 & \multirow{4}{*}{\multicolumn{2}{|c|}{ (1) }} & & & & \\
\hline & 5 & 73 & 9.1 & & & & & & \\
\hline & 6 & 114 & 14.3 & & & & & & \\
\hline & 7 & 178 & 22.3 & & & & & & \\
\hline Adj. 12 & \multicolumn{3}{|c|}{ FÁCIL/DIFÍCIL } & 10 & 20 & 30 & & 50 & 60 \\
\hline \multirow[b]{2}{*}{ Loco } & & Frecuencia & Porcentaje & \multirow{4}{*}{ : } & & & & & \\
\hline & 1 & 94 & 11.8 & & & & & & \\
\hline \multirow[b]{6}{*}{ Cuerdo } & 2 & 49 & 6.1 & & & & & & \\
\hline & 3 & 74 & 9.3 & & & & & & \\
\hline & 4 & 210 & 26.3 & \multirow[b]{2}{*}{ C } & & & & & \\
\hline & 5 & 70 & 8.8 & & & & & & \\
\hline & 6 & 126 & 15.8 & \multirow{2}{*}{ (1) } & & & & & \\
\hline & 7 & 174 & 21.8 & & & & & & \\
\hline Adj. 13 & \multicolumn{3}{|c|}{ LOCO/CUERDO } & 0 & 20 & 30 & & 50 & 60 \\
\hline
\end{tabular}

Por último, en un par de bipolaridades encontramos una distribución caracterizada por un aumento de la frecuencia en ambos extremos. Podemos interpretar que las personas seleccionaron un polo u otro: breve/ duradero y posible/ imposible. 
Tabla 9. Distribución de las respuestas en el cuarto grupo de adjetivos.

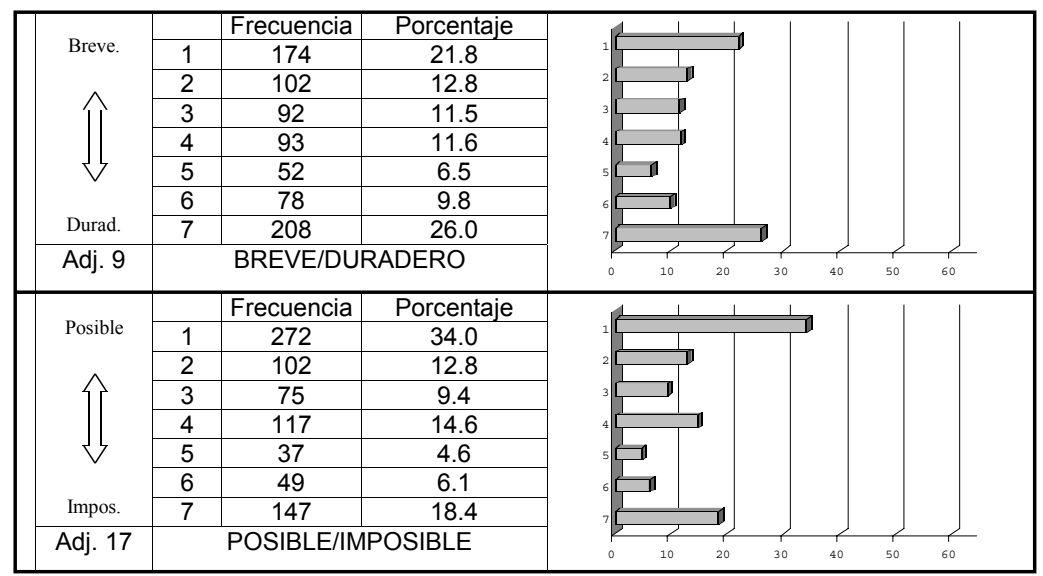

El cuarto grupo de adjetivos fueron incluidos en la presente investigación ya que la duración y la posibilidad o imposibilidad son características importantes en las relaciones amorosas. En futuros trabajos se analizarán las variables que explican las diferencias de respuesta entre los sujetos.

\section{Comentarios y conclusiones}

Los recuerdos son reconstrucciones imperfectas de las experiencias. Aunque un recuerdo de una experiencia emocional sea fuerte e intenso no es necesariamente exacto. Las evocaciones explícitas, independientemente de sus repercusiones emocionales, no son copias exactas de las experiencias que los crearon. Son reconstrucciones realizadas en el instante en que se recuerda (LeDoux, 1999).

Nuestras historias, amorosas o no, son construidas a partir de nuestras percepciones y, a su vez, nuestras experiencias, emociones, motivaciones y cogniciones afectan a nuestras historias de vida (Stemberg, 1998). Los recuerdos del pasado se reconstruyen y condensan en busca de mayor coherencia a lo largo del tiempo. La memoria no almacena de una manera fija. Coincidimos con Schater (1995) en cuanto a la conveniencia de reemplazar el concepto de almacenamiento por algún término diferente que no denote tanta fijeza.

En el conocido apartado sobre enamoramiento e hipnosis, en Psicología de las masas y análisis del yo, Freud sostiene que en el enamoramiento el objeto amado queda sustraído de toda crítica, siendo estimadas todas sus cualidades en el más alto valor. Lo que aquí falsea el juicio, aclara, es la tendencia a la idealización. 
Los datos que hemos analizado permiten afirmar que el primer amor no sólo es idealizado en el momento en que la experiencia es vivida, sino que su recuerdo conserva también esta característica. Los adjetivos utilizados para connotar el significado del primer enamoramiento lo ponen en evidencia ya que es considerado por la mayoría de los sujetos adultos como una relación amorosa buena, linda, sincera, limpia, valiosa, agradable, saludable y positiva.

El proyecto UBACyT del cual forma parte este trabajo( financiado por la Universidad de Buenos Aires y dirigido por M. M. Casullo) tiene como objetivo analizar las relaciones entre las emociones y la salud mental. Estudia los impactos salugénicos y patogénicos de las relaciones románticas. Los resultados obtenidos permiten afirmar que los sujetos vivencian y recuerdan su primer enamoramiento con características salugénicas.

\section{Referencias Bibliográficas}

Ackerman, D. (2000): Una historia natural de amor. Barcelona: Anagrama.

Alberoni, F. (1997). El primer amor. Barcelona: Gedisa.

Bartlett, F. (1932). Remembering. Cambridge: University Press.

Cohen, N. y Squire, L. (1980). Preserved learning and retention of pattern-analyzing skill in amnesia: Dissociation of Knowing how and knowing that. Science, 210, 207-209.

Freud, S. ( 1948). Obras completas. Madrid: Biblioteca Nueva.

Jacobs, W.L. y Nadel, L. (1985). Stress-induced recovery of fears and phobias. Psychological Review, 92, 512-531.

Osgood, C, Suci, G. y Tannembaum, P. (1957). The measurement of meaning. University of Illinois Press.

LeDoux, J. (1999). El cerebro emocional. Barcelona: Planeta.

Schater, D. (1995). Memory distortion. How minds, bains and societies reconstruct the past. Cambridge. Massachusetts. Harvard: University Press.

Stemberg, R. J. (1998). El amor es como una historia. Barcelona: Paidós. 
Psicodebate. Psicología, Cultura y Sociedad

Tulving, E. y Donadlson, W. (1972) Organization of memory. NY: Academic Press. (1983) Elements of episodic memory. Nueva York, Oxford: University Press. 